\title{
Prevalence of G6PD Viangchan variant in malaria endemic areas in Lao PDR: an implication for malaria elimination by 2030
}

\author{
Ken Ing Cherng Ong ${ }^{1,2+}$, Moritoshi Iwagami ${ }^{2,3,4 \dagger}$, Hitomi Araki ${ }^{1,2}$, Phonepadith Khattignavong ${ }^{2,4}$, \\ Pheovaly Soundala 2,4, Sengdeuane Keomalaphet ${ }^{2,4}$, Phoyphaylinh Prasayasith ${ }^{2,4}$, Lavy Lorpachan ${ }^{2,4}$, \\ Phonepadith Xangsayalath ${ }^{2,4,5,6}$, Tiengkham Pongvongsa ${ }^{7}$, Bouasy Hongvanthong ${ }^{2,8}$, Paul T. Brey ${ }^{2,4}$, \\ Shigeyuki Kano ${ }^{2,3,4}$ and Masamine Jimba ${ }^{12^{*}}$
}

\begin{abstract}
Background: Primaquine is effective against the latent liver stage of Plasmodium vivax. Eliminating the latent liver stage of P. vivax is one of the necessary conditions to achieve the goal of malaria elimination in Lao People's Democratic Republic (PDR) by 2030. However, people with glucose-6-phosphate dehydrogenase (G6PD) deficiency are at risk of haemolysis when ingesting primaquine. The aim of this study was to detect the prevalence of the G6PD Viangchan variant, which is said to be common in Lao PDR and which can result in severe haemolysis in patients exposed to primaquine.
\end{abstract}

Methods: Blood samples were collected from villagers in three malaria endemic provinces: Champasak and Savannakhet in the south, and Phongsaly in the north. Each blood sample was semi-quantitatively assayed for G6PD enzyme activity using the G6PD Assay Kit-WST Lyophilized (DOJINDO Laboratories, Japan). Blood samples that were found to be G6PD deficient were sequenced to detect G6PD Viangchan mutation.

Results: In total, 2043 blood samples were collected from Phongsaly ( $n=426,20.9 \%)$, Savannakhet $(n=924,45.2 \%)$, and Champasak $(n=693,33.9 \%)$ provinces in Lao PDR from 2016 to 2017. Of these, 964 (47.2\%) were taken from male villagers and 1079 (52.8\%) were taken from female villagers. G6PD Viangchan mutation was not detected in Phongsaly province in this study. In Savannakhet province, 48 of the 924 samples (45 males, 3 females) had the G6PD Viangchan mutation ( $n=48,5.2 \%$ ). In Champasak province, 42 of the 693 samples (18 males, 24 females) had the G6PD Viangchan mutation $(n=42,6.1 \%)$.

Conclusions: G6PD Viangchan variant, which can cause severe haemolysis in the carrier when exposed to primaquine, was detected among 6.1\% of the villagers in Champasak and 5.2\% in Savannakhet but not in Phongsaly in this study. G6PD Viangchan variant might be common in the south of Laos but not so in the north. In the north, other G6PD deficiency variants might be more prevalent. However, in order not to overlook anyone and ensure a safe primaquine therapy for people living in malaria endemic areas in Lao PDR, G6PD testing is necessary.

Keywords: Laos, Glucose-6-phosphate dehydrogenase deficiency, Plasmodium vivax, Malaria elimination

\footnotetext{
*Correspondence: mjimba@m.u-tokyo.ac.jp

${ }^{t}$ Ken Ing Cherng Ong and Moritoshi Iwagami contributed equally to this

work

1 Department of Community and Global Health, Graduate School

of Medicine, The University of Tokyo, Tokyo, Japan

Full list of author information is available at the end of the article
} 


\section{Background}

Worldwide, 219 million malaria cases were reported and 435,000 lives were lost to the disease in 2017 [1]. In Lao People's Democratic Republic (PDR), 8417 malaria cases were reported nationwide from December 2017 to November 2018 [2]. Since 2010, the proportion of Plasmodium vivax cases has been increasing and in 2016, $61 \%$ of the total reported malaria cases were caused by P. vivax [3]. Malaria is endemic throughout Lao PDR but $95 \%$ of all reported cases were from the five southern provinces of Savannakhet, Saravane, Champasak, Sekong, and Attapeu [4].

Compared to falciparum malaria, vivax malaria has received less attention due to the flawed assumption that it is less severe and less life-threatening [5]. However, recent studies have indicated that vivax malaria is not benign [6, 7]. Although $P$. vivax threatens almost $40 \%$ of the world's population, the burden, economic impact, and severity of the disease are underestimated [6]. Unlike falciparum malaria which causes a single attack after a single infectious bite by the anopheline mosquito, vivax malaria results in multiple clinical attacks over several months up to two years after a single infectious bite [8]. Moreover, the liver reservoir of $P$. vivax in asymptomatic carriers in an endemic community may indeed be greater than expected due to its longer incubation period compared to P. falciparum $[6,7,9]$.

Nevertheless, vivax malaria cases in Lao PDR might have been underestimated as only provincial and district hospitals are equipped with microscopy to conduct species specific analysis and treatment [10]. At the health centre level, malaria diagnosis is conducted using rapid diagnostic test (RDT) [10]. In Lao PDR, combo RDT (Malaria Ag P.f/P.v, Standard Diagnostics, Inc. Republic of Korea) is used for malaria diagnosis, which can differentiate between $P$. falciparum and $P$. vivax. However, the RDT has lower sensitivity towards detecting $P$. vivax when compared to $P$. falciparum $[10,11]$.

To prevent relapse caused by the dormant liver stage (hypnozoite) in vivax malaria, only one drug is available and that is primaquine [12]. In Lao PDR, a standard treatment regimen of primaquine for hypnozoite elimination is $0.25 \mathrm{mg} / \mathrm{kg}$ for 14 days. Primaquine (singlelow-dose) is also effective against the gametocyte stage of falciparum malaria and this treatment regimen is also adopted in Lao PDR [1]. However, primaquine causes acute haemolytic anaemia in patients with glucose-6-phosphate dehydrogenase (G6PD) deficiency [12]. Glucose-6-phosphate dehydrogenase is an enzyme that protects the red blood cells from oxidative stress caused by consumption of certain food or medicines [13]. The gene encoding G6PD is located on the X-chromosome and consists of 13 exons [14]. As the gene for G6PD is X-linked, the enzyme activity for males is either normal or deficient, whereas the enzyme activity for females is normal, deficient, or intermediate $[15,16]$. Almost 190 G6PD mutations have been identified and most of them are missense mutations $[17,18]$.

Despite G6PDd being common in the Greater Mekong Subregion, information on G6PDd from the area is scant $[19,20]$. However, studies have reported the presence of the Canton, Chinese-4, Kaiping, Mahidol, Union, and Viangchan variants in the Greater Mekong Subregion $[21,22]$. Hence, to prevent relapse from vivax malaria, to control the spread of vivax malaria, and also to achieve malaria elimination in Lao PDR, it is necessary to prescribe primaquine to malaria patients. Therefore, to avoid any life-threatening complications, a patient's G6PD status must first be identified before prescribing primaquine $[23,24]$. This is in line with the policy adopted by the government of Lao PDR to prescribe primaquine only after the G6PD status of the patient is identified [25].

The aim of this study was to detect the prevalence of G6PD Viangchan deficiency in malaria endemic areas in Phongsaly, Savannakhet, and Champasak provinces in Lao PDR. It is hoped that the findings from this study will contribute to the decision making in the context of primaquine prescription among healthcare providers in these areas in the future.

\section{Methods}

\section{Study areas and study populations}

This study was conducted in Champasak province in February 2016, Phongsaly province in February 2017, and Savannakhet province in November 2016 and October 2017. These three provinces were selected because of the high number of reported malaria cases and also a relatively high number of reported vivax malaria cases [2]. Moreover, as Lao PDR is an ethnically diverse country [26], the prevalence of G6PDd among different ethnic groups living in these three provinces was also assessed. In each province, two to three districts with the highest number of malaria cases were selected based on the data of the Center of Malariology, Parasitology and Entomology, Ministry of Health [27]. At the district level, the villages were selected after consultation with the district health office (Fig. 1).

In each village, the village head was requested to inform the entire village about the survey. As malaria affects all regardless of age and gender, all villagers who were present on the day of the survey were included.

\section{Blood collection procedure}

Blood was collected from each villager through a finger prick. Two hundred fifty $\mu \mathrm{l}$ of blood was collected on a filter paper $\left(\right.$ FTA $^{\mathrm{TM}}$ Classic Card, Whatman ${ }^{\mathrm{TM}}$, GE 


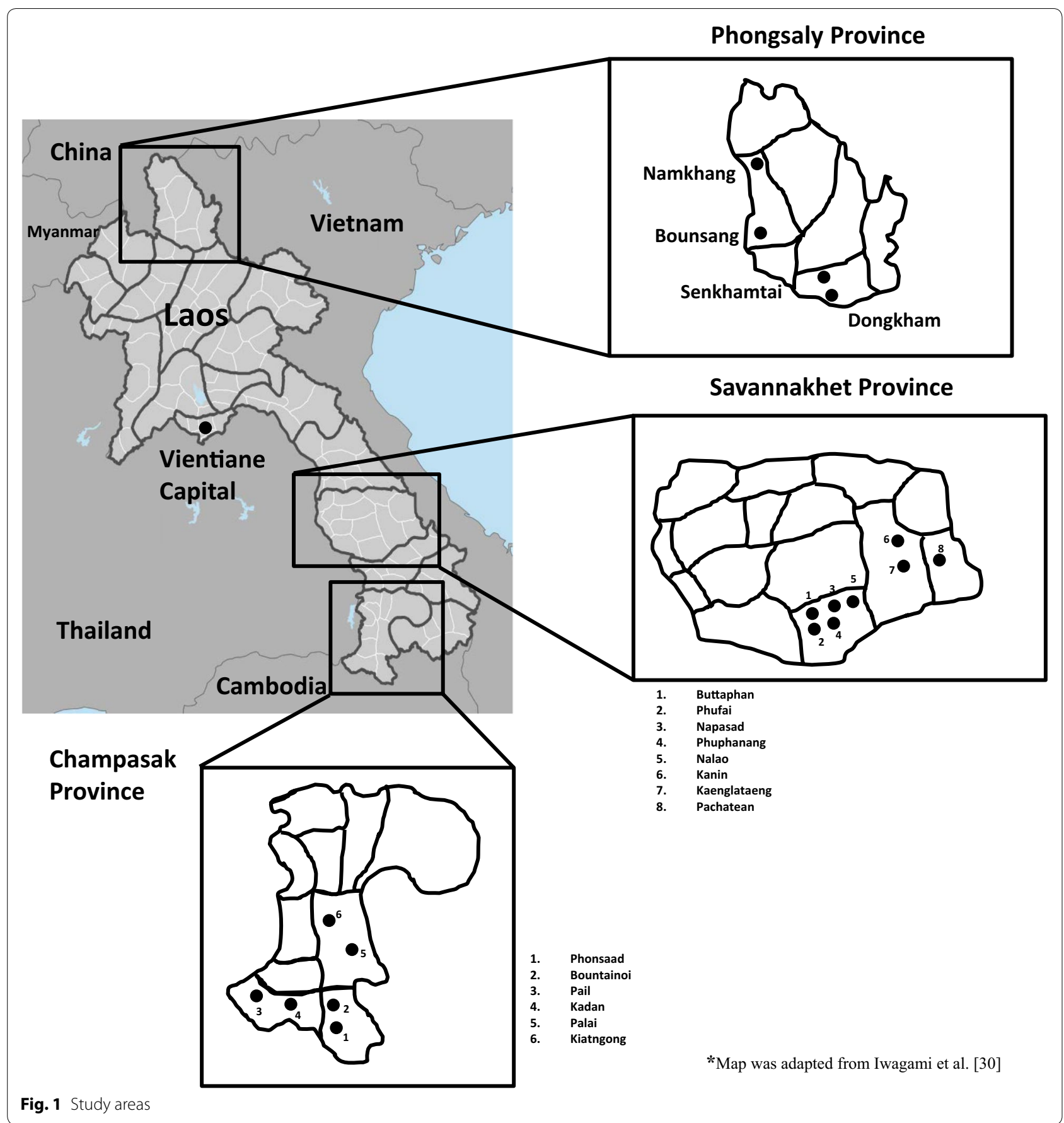

Healthcare Life Sciences, UK) for analysis of the G6PD gene. Ten $\mu \mathrm{l}$ of blood was used for thick and thin blood smear for malaria diagnosis by microscopy.

\section{G6PD enzyme activity semiquantitative test}

G6PD Assay Kit-WST lyophilized (DOJINDO Laboratories, Japan) was used for enzyme activity assay. From the $10 \mu \mathrm{l}$ of blood collected from each villager, $5 \mu \mathrm{l}$ of blood was mixed with the substrate and dye mixture for testing and $5 \mu \mathrm{l}$ of blood was mixed with only dye mixture for negative control according to the manufacturer's manual. After mixing the blood with the solution, the tubes were placed in an icebox immediately to stop further reaction. The tubes were later transported to the research team's guesthouse for further analysis within the same day of blood collection. 
At the guesthouse where a makeshift laboratory had been set up, the samples were incubated for $30 \mathrm{~min}$ at $37.0{ }^{\circ} \mathrm{C}$. After the incubation, the enzyme activity was measured using a NanoDrop 2000c UV-Vis Spectrophotometer (Thermo Fisher Scientific Inc. USA). Absorbance was measured at $450 \mathrm{~nm}$ and the background color was subtracted using the negative control. To obtain the calibration curve, a blood sample with normal G6PD activity was used as a positive control. The enzyme activities for all other samples were measured against the positive control according to the manufacturer's instruction. Samples with enzyme activity less than $60.0 \%$ of the positive control were selected for further genetic analysis.

\section{Genetic analysis of the G6PD gene}

The dried blood samples on the filter papers were transported from the field to the Institut Pasteur du Laos (IPL) in Vientiane for genetic analyses. DNA was extracted from the dried blood samples on the filter paper using the QIAamp DNA Mini Kit (Qiagen, Germany) according to the manufacturer's instructions.

Exon 9 of the G6PD gene was sequenced to detect G6PD Viangchan mutation $(871 \mathrm{G}>\mathrm{A})$. The primer set (Sense primer: ACCCAAGGAGCCCATTC; Antisense primer: ACACAGGGCATGCCCAGTTCTG) for Exon 9 of the G6PD gene previously reported by Matsuoka et al. was used [14]. For conventional PCR, TaKaRa Tks Gflex $^{\text {TM }}$ DNA Polymerase (TaKaRa Bio, Japan) was used. For DNA sequencing, BigDye ${ }^{\circledR}$ Terminator v3.1 Cycle Sequencing Kit (Thermo Fisher Scientific Inc. USA) was used and subsequently the DNA sequence was read with a 3500 XL Genetic Analyzer (Applied Biosystems, Thermo Fisher Scientific Inc. USA).

The sequencing results were analysed by ClustalW in MEGA software version 7.0.21 using glucose-6-phosphate 1-dehydrogenase isoform b [Homo sapiens] sequence as a reference (Accession: NP_001035810.1).

\section{Ethical considerations}

This study was approved by the National Ethics Committee for Health Research (NECHR), National Institute of Public Health (NIOPH), Ministry of Health, Lao PDR (No. 049 NIOPH/NECHR) and the Research Ethics Committee of the University of Tokyo (No. 11123). Participation was voluntary and a written informed consent was obtained from all participants and from the parents or guardians of those under 18 years of age.

\section{Results}

In total, 2043 blood samples were collected from Phongsaly $(\mathrm{n}=426,20.9 \%)$, Savannakhet $(\mathrm{n}=924,45.2 \%)$, and Champasak $(\mathrm{n}=693,33.9 \%)$ provinces in Lao PDR from 2016 to 2017. Out of 2043 blood samples, 964 (47.2\%) were from male villagers and 1079 (52.8\%) were from female villagers. The G6PD Viangchan mutation was not detected among the 426 blood samples from Phongsaly province in this study. In Savannakhet province, 48 blood samples (45 males, 3 females) out of 924 blood samples showed the G6PD Viangchan mutation $(\mathrm{n}=48,5.2 \%)$. In Champasak province, 42 blood samples (18 males, 24 females) out of 693 blood samples showed the G6PD Viangchan mutation $(n=42,6.1 \%)$ (Table 1$)$.

The percentage of villagers carrying the G6PD Viangchan mutation ranged from $1.7 \%$ in Pachatean village, Nong district, Savannakhet province to $12.7 \%$ in Phuphanang village, Thapangthong district, Savannakhet province (Table 1 ).

The allelic frequencies of Viangchan mutation for each village were calculated and ranged from $1.09 \%$ in Pachatean village, Nong district, Savannakhet province to $9.33 \%$ in Phuphanang village, Thapangthong district, Savannakhet province (Table 1).

The number of malaria cases confirmed by microscopy is shown in Table 2. Information on the age and sex of the villagers is summarized in Additional file 1: Appendix S1.

\section{Discussion}

The main aim of this study was to screen for the G6PD Viangchan mutation among 2043 villagers from different ethnic groups in Phongsaly, Savannakhet, and Champasak provinces. In Savannakhet province and Champasak province, $5.2 \%$ and $6.1 \%$ of the villagers were found to carry the G6PD Viangchan mutation respectively. However, G6PD Viangchan mutation was not observed among the ethnic groups in Phongsaly. This might be due to G6PD Viangchan not being common among the ethnic groups in that area. The results in this study are consistent with the predicted G6PD deficiency prevalence of $1-23 \%$ across Lao PDR [19]. As G6PD Viangchan is more common among the Lao and Thai population, this might explain why G6PD Viangchan was not detected among the population in Phongsaly province who are of a different ethnic group [28]. Severe haemolysis could occur in people with G6PD Viangchan mutation when under oxidative stress caused by agents such as primaquine [29, 30].

In this study, all the villages were in remote locations and far away from the district and provincial hospitals. In Lao PDR, G6PD testing is required before primaquine prescription since 2010 [3]. However, at the moment, G6PD rapid diagnostic tests are only available at the provincial or district hospital levels. As many patients live in remote villages, many of them are reluctant to go to either the district or provincial hospitals when advised to (personal communication with a local healthcare worker). Unless primaquine and G6PD testing are 


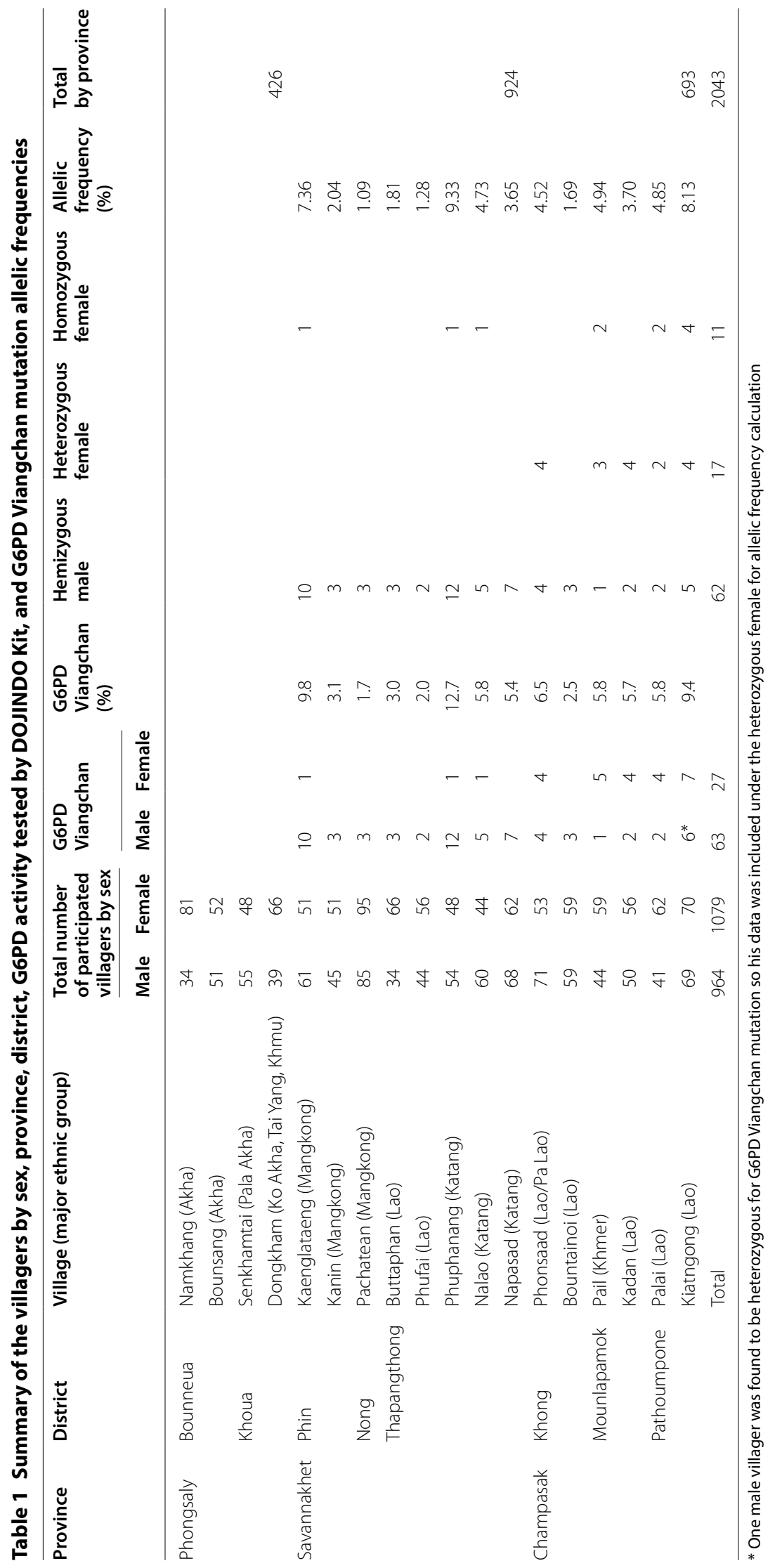


Table 2 Number of malaria cases confirmed by microscopy

\begin{tabular}{|c|c|c|c|c|c|c|c|c|c|}
\hline \multirow[t]{2}{*}{ Province } & \multirow[t]{2}{*}{ District } & \multirow[t]{2}{*}{ Village (major ethnic group) } & \multicolumn{2}{|c|}{$\begin{array}{l}\text { Total number } \\
\text { of participated } \\
\text { villagers by sex }\end{array}$} & \multicolumn{2}{|c|}{$\begin{array}{l}\text { Pf positive } \\
\text { by microscopy }\end{array}$} & \multicolumn{2}{|c|}{$\begin{array}{l}\text { Pv positive } \\
\text { by microscopy }\end{array}$} & \multirow[t]{2}{*}{$\begin{array}{l}\text { Total } \\
\text { by province }\end{array}$} \\
\hline & & & Male & Female & Male & Female & Male & Female & \\
\hline \multirow[t]{4}{*}{ Phongsaly } & Bounneua & Namkhang (Akha) & 34 & 81 & & & & & \\
\hline & & Bounsang (Akha) & 51 & 52 & & & & & \\
\hline & Khoua & Senkhamtai (Pala Akha) & 55 & 48 & & & 3 & 1 & \\
\hline & & Dongkham (Ko Akha, Tai Yang, Khmu) & 39 & 66 & & & & & 426 \\
\hline \multirow[t]{8}{*}{ Savannakhet } & Phin & Kaenglataeng (Mangkong) & 61 & 51 & & 1 & & & \\
\hline & & Kanin (Mangkong) & 45 & 51 & & & & & \\
\hline & Nong & Pachatean (Mangkong) & 85 & 95 & 1 & 1 & & & \\
\hline & Thapangthong & Buttaphan (Lao) & 34 & 66 & & & & & \\
\hline & & Phufai (Lao) & 44 & 56 & & & & & \\
\hline & & Phuphanang (Katang) & 54 & 48 & & & & & \\
\hline & & Nalao (Katang) & 60 & 44 & & & & & \\
\hline & & Napasad (Katang) & 68 & 62 & & & & & 924 \\
\hline \multirow[t]{7}{*}{ Champasak } & Khong & Phonsaad (Lao/Pa Lao) & 71 & 53 & & 1 & & & \\
\hline & & Bountainoi (Lao) & 59 & 59 & & 1 & & & \\
\hline & Mounlapamok & Pail (Khmer) & 44 & 59 & 1 & & 1 & & \\
\hline & & Kadan (Lao) & 50 & 56 & & & & & \\
\hline & Pathoumpone & Palai (Lao) & 41 & 62 & 2 & 2 & 1 & & \\
\hline & & Kiatngong (Lao) & 69 & 70 & 7 & $3^{*}$ & & $1^{*}$ & 693 \\
\hline & & Total & 964 & 1079 & 11 & 9 & 5 & 2 & 2043 \\
\hline
\end{tabular}

* Mixed infection, counted twice

made available at the village level, elimination will not be achieved. Moreover, strict pharmacovigilance, which includes monitoring and measuring the haemoglobin level and haematocrit values, is also recommended alongside primaquine use. However, health centres at the village level still lack the capacity to conduct these tests. This also highlights the necessity of improving the quality of health centres at the village level.

Asymptomatic Plasmodium carriers are quite common in Lao PDR and a sizeable proportion of them are due to $P$. vivax [31]. This suggests the necessity of employing primaquine to eliminate the latent liver reservoirs to achieve the elimination goal by 2030. However, as G6PD deficiency is prevalent in malaria endemic areas in Lao PDR, and severe complications can result in the case of G6PD Viangchan mutation, G6PD screening has the potential to avoid unnecessary loss of lives in these endemic areas. In addition, as G6PD deficiency also affects the presentation of other diseases such as typhoid fever and dengue fever which are prevalent in Lao PDR, the benefits of knowing whether or not a person has G6PD deficiency could extend beyond the context of malaria [32].

In this study, the prevalence of only G6PD Viangchan was reported. However, other G6PD deficiency variants such as the Canton, Chinese-4, Kaiping, Mahidol, and Union have been reported in Lao PDR as well as other Greater Mekong Subregion countries [21, 22]. This emphasizes the importance of conducting thorough G6PD screening before primaquine prescription to ensure patient safety. Moreover, participant selection in this study was based on a voluntary basis therefore the prevalence in this study might not reflect the prevalence in the general population.

The villagers were not asked about their illness history in this study. However, recent haemolytic events can also affect a villager's G6PD activity. A patient with G6PD enzyme deficiency who had a recent haemolytic event might have a higher proportion of young red blood cells with higher G6PD activity and this could potentially mislead result using the semiquantitative G6PD Assay KitWST lyophilized (DOJINDO Laboratories, Japan) [33]. This could result in the G6PD deficiency in this study being underestimated.

\section{Conclusions}

In conclusion, G6PD Viangchan, which could cause severe haemolysis in the carrier if exposed to primaquine, was prevalent in Savannakhet and Champasak provinces, but not in Phongsaly province in this study. As Lao PDR is aiming to eliminate malaria by 2030 , primaquine is 
indispensable. However, dispensing of primaquine without reliable G6PD testing could cause severe complications among people who have G6PD deficiency [25]. Even though blood transfusion could save lives, the procedure itself carries risks, is costly, and blood supply might be unavailable in this setting [34]. Due to the high prevalence of G6PD deficiency among people living in endemic areas, thorough and systematic G6PD screening is indispensable as the benefits could go beyond the context of malaria elimination. As strict pharmacovigilance is also recommended alongside primaquine, improving the quality of the facilities and the skills of the healthcare providers at the village level is necessary.

\section{Additional file}

Additional file 1: Appendix S1. Villagers'information.

\section{Abbreviations \\ Lao PDR: Lao People's Democratic Republic; G6PDd: Glucose-6-phosphate dehydrogenase deficiency.}

\section{Authors' contributions}

$\mathrm{KICO}$ and $\mathrm{MI}$ conceived and designed this study. KICO, MI, HA, PK, PS, SKe, $\mathrm{PP}, \mathrm{LL}$ and PX collected samples. KICO and MI performed the experiment and analysis of DNA data. KICO wrote the manuscript. All authors read and approved the final manuscript.

\section{Author details \\ ${ }^{1}$ Department of Community and Global Health, Graduate School of Medi- cine, The University of Tokyo, Tokyo, Japan. ${ }^{2}$ SATREPS Project (JICA/AMED) for Parasitic Diseases, Vientiane, Lao People's Democratic Republic. ${ }^{3}$ Depart- ment of Tropical Medicine and Malaria, Research Institute, National Centre for Global Health and Medicine, 1-21-1 Toyama, Shinjuku, Tokyo 162-8655, Japan. ${ }^{4}$ Institut Pasteur du Laos, Ministry of Health, Samsenthai Road, Ban Kao-Gnot, Sisattanak District, P.O. Box 3560, Vientiane, Lao People's Democratic Republic. ${ }^{5}$ National Institute of Public Health, Ministry of Health, Vientiane, Lao People's Democratic Republic. ${ }^{6}$ Present Address: National Center for Labora- tory and Epidemiology, Ministry of Health, Vientiane, Lao People's Democratic Republic. ${ }^{7}$ Savannakhet Provincial Health Department, Kaysone-Phomvihan District, Savannakhet, Lao People's Democratic Republic. ${ }^{8}$ Center of Malariol- ogy, Parasitology and Entomology, Ministry of Health, Vientiane, Lao People's Democratic Republic.}

\section{Acknowledgements}

The authors would like to thank all the villagers and staff members in the public health care facilities in Phongsaly, Savannakhet, and Champasak provinces in Lao PDR. We are grateful to Mr. Tetsuo Yamashita, Ms. Kimiko Masuda, and Mr. Yasumasa Nagaoka, JICA SATREPS Project Coordinators.

\section{Competing interests}

The authors declare that they have no competing interests.

\section{Availability of data}

The dataset is included in this published article and its additional file.

\section{Ethical consideration}

This study was approved by the National Ethics Committee for Health Research (NECHR), National Institute of Public Health (NIOPH), Ministry of Health, Lao PDR (No. 049 NIOPH/NECHR) and the Research Ethics Committee of the University of Tokyo (No. 11123). Participation was voluntary and a written informed consent was obtained from all participants and from the parents or guardians of those under 18 years of age.

\section{Funding}

This study was financially supported by the JICA/AMED SATREPS project for the "Development of innovative research techniques in the genetic epidemiology of malaria and other parasitic diseases in the Lao PDR for containing their expanding endemicity."

\section{Publisher's Note}

Springer Nature remains neutral with regard to jurisdictional claims in published maps and institutional affiliations.

Received: 10 January 2019 Accepted: 8 March 2019

Published online: 12 March 2019

\section{References}

1. WHO. World Malaria Report 2018. Geneva: World Health Organization; 2018.

2. District Health Information System version 2 (DHIS2). Lao People's Democratic Republic.2018. https://hmis.gov.la/dhis-web-commons/security/ login.action. Accessed 1 December 2018.

3. WHO. Malaria country profiles: Lao People's Democratic Republic. Geneva: World Health Organization; 2018. https://www.who.int/malaria/ publications/country-profiles/profile_lao_en.pdf. Accessed 3 Dec 2018.

4. Ministry of Health of the Lao People's Democratic Republic. National Strategy for Malaria Control and Elimination 2015-2020. Vientiane. 2015.

5. Rahimi BA, Thakkinstian A, White NJ, Sirivichayakul C, Dondorp AM, Chokejindachai W, et al. Severe vivax malaria: a systematic review and meta-analysis of clinical studies since 1900. Malar J. 2014;13:481

6. Price RN, Tjitra E, Guerra CA, Yeung S, White NJ, Anstey NM, et al. Vivax malaria: neglected and not benign. Am J Trop Med Hyg. 2007;77:79-87.

7. Baird JK. Malaria caused by Plasmodium vivax: recurrent, difficult to treat, disabling, and threatening to life-the infectious bite preempts these hazards. Pathog Glob Health. 2013;107:475-9.

8. Baird JK. Evidence and implications of mortality associated with acute Plasmodium vivax malaria. Clin Microbiol Rev. 2013;26:36-57.

9. Gething PW, Elyazar IR, Moyes CL, Smith DL, Battle KE, Guerra CA, et al. A long neglected world malaria map: Plasmodium vivax endemicity in 2010. PLoS Negl Trop Dis. 2012;6:e1814.

10. Ministry of Health of the Lao People's Democratic Republic. National Strategy for Malaria Control and Pre-Elimination 2011-2015. Vientiane. 2010.

11. Fransisca L, Kusnanto JH, Satoto TB, Sebayang B, Andriyan E, et al. Comparison of rapid diagnostic test Plasmotec Malaria-3, microscopy, and quantitative real-time PCR for diagnoses of Plasmodium falciparum and Plasmodium vivax infections in Mimika Regency, Papua, Indonesia. Malar J. 2015:14:103.

12. Baird JK. Origins and implications of neglect of G6PD deficiency and primaquine toxicity in Plasmodium vivax malaria. Pathog Glob Health. 2015;109:93-106.

13. Beutler E, Duparc S, Group GPDW. Glucose-6-phosphate dehydrogenase deficiency and antimalarial drug development. Am J Trop Med Hyg. 2007;77:779-89.

14. Matsuoka $H$, Thuan DTV, van Thien $H$, Kanbe T, Jalloh A, Hirai M, et al. Seven different glucose-6-phosphate dehydrogenase variants including a new variant distributed in Lam Dong Province in southern Vietnam. Acta Med Okayama. 2007;61:213-9.

15. Cappellini MD, Fiorelli G. Glucose-6-phosphate dehydrogenase deficiency. Lancet. 2008;371:64-74.

16. Luzzatto L. Glucose 6-phosphate dehydrogenase deficiency: from genotype to phenotype. Haematologica. 2006;91:1303-6.

17. Frank JE. Diagnosis and management of G6PD deficiency. Am Fam Physician. 2005;72:1277-82.

18. Minucci A, Moradkhani K, Hwang MJ, Zuppi C, Giardina B, Capoluongo E, et al. Glucose-6-phosphate dehydrogenase (G6PD) mutations database: review of the "old" and update of the new mutations. Blood Cells Mol Dis. 2012:48:154-65. 
19. Howes RE, Piel FB, Patil AP, Nyangiri OA, Gething PW, Dewi M, et al. G6PD deficiency prevalence and estimates of affected populations in malaria endemic countries: a geostatistical model-based map. PLoS Med. 2012;9:e1001339.

20. Wiwanitkit V. Genetic disorders and malaria in Indo-China region. J Vector Borne Dis. 2008;45:98-104.

21. Lover AA, Dantzer E, Hongvanthong B, Chindavongsa K, Welty S, Reza T, et al. Prevalence and risk factors for asymptomatic malaria and genotyping of glucose 6-phosphate (G6PD) deficiencies in a vivax-predominant setting, Lao PDR: implications for sub-national elimination goals. Malar J. 2018:17:218.

22. Bancone G, Menard D, Khim N, Kim S, Canier L, Nguong C, et al. Molecular characterization and mapping of glucose-6-phosphate dehydrogenase (G6PD) mutations in the Greater Mekong Subregion. Malar J. 2019;18:20.

23. Monteiro WM, Franca GP, Melo GC, Queiroz AL, Brito M, Peixoto HM, et al. Clinical complications of G6PD deficiency in Latin American and Caribbean populations: systematic review and implications for malaria elimination programmes. Malar J. 2014;13:70.

24. Monteiro WM, Val FF, Siqueira AM, Franca GP, Sampaio VS, Melo GC, et al. G6PD deficiency in Latin America: systematic review on prevalence and variants. Mem Inst Oswaldo Cruz. 2014;109:553-68.

25. WHO. Point-of-care G6PD testing to support safe use of primaquine for the treatment of vivax malaria. Geneva: World Health Organization; 2015.

26. Messerli P, Heinimann A, Epprecht M, Phonesaly S, Thiraka C, Minot N, et al. Socio-economic atlas of the Lao PDR an analysis based on the 2005 population and housing census. Swiss National Center of Competence in Research (NCCR) North-South and Geographica Bernensia. 2008.
27. Center for Malaria Parasitology and Entomology. Vientiane. 2015.

28. Howes RE, Dewi M, Piel FB, Monteiro WM, Battle KE, Messina JP, et al. Spatial distribution of G6PD deficiency variants across malaria-endemic regions. Malar J. 2013;12:418.

29. Ashley EA, Recht J, White NJ. Primaquine: the risks and the benefits. Malar J. 2014;13:418.

30. Chu CS, Bancone G, Moore KA, Win HH, Thitipanawan N, Po C, et al. Haemolysis in G6PD heterozygous females treated with primaquine for Plasmodium vivax malaria: a nested cohort in a trial of radical curative regimens. PLoS Med. 2017;14:e1002224.

31. Iwagami M, Keomalaphet $S$, Khattignavong P, Soundala P, Lorphachan L, Matsumoto-Takahashi E, et al. The detection of cryptic Plasmodium infection among villagers in Attapeu province, Lao PDR. PLoS Negl Trop Dis. 2017;11:e0006148.

32. Ong KIC, Kosugi H, Thoeun S, Araki H, Thandar MM, Iwagami M, et al. Systematic review of the clinical manifestations of glucose-6-phosphate dehydrogenase deficiency in the Greater Mekong Subregion: implications for malaria elimination and beyond. BMJ Glob Health. 2017;2:e000415.

33. Domingo GJ, Satyagraha AW, Anvikar A, Baird K, Bancone G, Bansil P, et al. G6PD testing in support of treatment and elimination of malaria: recommendations for evaluation of G6PD tests. Malar J. 2013;12:391.

34. Goodnough LT, Levy JH, Murphy MF. Concepts of blood transfusion in adults. Lancet. 2013;381:1845-54
Ready to submit your research? Choose BMC and benefit from:

- fast, convenient online submission

- thorough peer review by experienced researchers in your field

- rapid publication on acceptance

- support for research data, including large and complex data types

- gold Open Access which fosters wider collaboration and increased citations

- maximum visibility for your research: over 100M website views per year

At BMC, research is always in progress.

Learn more biomedcentral.com/submissions 